\title{
Impressum
}

\section{KAS African Law Study Library - Librairie Africaine d'Etudes Juridiques}

Herausgeber: Konrad-Adenauer-Stiftung e.V., Klingelhöferstraße 23, 10785 Berlin

Schriftleitung: RA Prof. Dr. Hartmut Hamann, Falkertstraße 82, D-70193 Stuttgart Telefon: +49 (o) 711 120950-30 | Fax : +49 (o) 711 120950-50

Mail: hamann@hamann-legal.de

Erscheinungsweise: 4 Ausgaben pro Jahr

Druck und Verlag: Nomos Verlagsgesellschaft mbH \& Co. KG - Waldseestr. 3-5 D-76530 Baden-Baden. Telefon +49-7221-2104-0 / Fax 49-7221-2104-27

E-Mail:nomos@nomos.de

Anzeigen: sales friendly Verlagsdienstleistungen - Inh. Frau Bettina Roos - Pfaffenweg 15-D-53227 Bonn Telefon +49-228-97898-o / Fax +49-228-97898-20 E-Mail: roos@sales-friendly.de

Urheber- und Verlagsrechte: Die Zeitschrift und alle in ihr enthaltenen einzelnen Beiträge sind urheberrechtlich geschützt. Jede Verwertung außerhalb der engen Grenzen des Urheberrechtsgesetzes ist ohne Zustimmung des Verlages unzulässig. Das gilt insbesondere für Vervielfältigungen, Übersetzungen, Mikroverfilmungen und die Einspeicherung und Verarbeitung in elektronischen Systemen. Der Nomos Verlag beachtet die Regeln des Börsenvereins des Deutschen Buchhandels e.V. zur Verwendung von Buchrezensionen.

ISSN $2363-6262$

\section{Nomos}

